\title{
Towards the Valuation of Open Spaces: A Hedonic Based Investigation for Sustainable Planning in the Dense Urban Context of Dhaka
}

\author{
Faria Sharmin \\ Department of Architecture, Stamford University Bangladesh, Dhaka, Bangladesh \\ Email address: \\ faria.sharmin.buet@gmail.com, f_sharmin@stamforduniversity.edu.bd

\section{To cite this article:} \\ Faria Sharmin. Towards the Valuation of Open Spaces: A Hedonic Based Investigation for Sustainable Planning in the Dense Urban Context \\ of Dhaka. American Journal of Environmental and Resource Economics. Vol. 5, No. 4, 2020, pp. 97-103. doi: 10.11648/j.ajere.20200504.13
}

Received: August 28, 2020; Accepted: October 19, 2020; Published: November 19, 2020

\begin{abstract}
Within the context of the economic valuation, the presence and absence of open space has an effect on the residential property value in urban areas. Residents in a city esteemed these open spaces differently. They are keen to pay a premium for attractive views willingly. This study only assessed the amenity value of open spaces especially green parks and water bodies of two planned urban residential neighborhoods of Dhaka city in Economic terms. An empirical analysis is carried out by employing Hedonic Price Method (HPM) to analyze the impact of open space attributes on real price of residential properties. The six storied walkup and high-density apartments are typical for upper and middle-income residents in Dhaka city. Together with a set of structural, location and socio-economic variables the research use to explain residential property prices; this study focuses on three amenity or environmental variables which include the existence of views of open spaces, the distance from the residential unit to the nearest open space, and the size of that open space. The regression analysis result from the first stage hedonic estimation reveal that homebuyers are willing to pay only for scenic views and living in the closest proximity to open spaces especially green parks. In contrast results for the size of the nearest open space for houses do not show a significant relationship on nearby property values. This estimated valuation of open spaces and their amenity benefits will be useful for policy making in urban design for both developers and planners, composing new strategies for land use planning and sustainable development, open space conservation and property appraisal.
\end{abstract}

Keywords: Urban Open Space, Economic Valuation, Residential Property Price, Hedonic Price Method

\section{Introduction}

Open spaces and public recreation lands enhance the environment, economy and quality of life in cities by improving air quality, providing recreational opportunities, and enhancing aesthetic values, among many other benefits. In many cities, parks and other open spaces have traditionally been publicly provided facilities for which no price has been established in the market place [1]. To ensure the contribution of open spaces, they must be adequately provided and well planned, designed and maintained. As cities grow, however, open areas are habitually transformed to create space for new infrastructures necessitate to accommodate the increasing urban population. Diverse landscape elements such as parks, fields, water bodies etc in cities are esteemed differently by people. Residents are keen to pay a premium for attractive views. Within the context of economic outlook, the valuation of urban open space is difficult to quantify because it is a classic public good, where there is no market value. As a result, the people may pay no attention to such benefits in their planning. Apparent lack of understanding the economics of open space obstructs proper justification in cost-benefit analyses. Thus people may not attain any noticeable benefits from such open spaces in their city planning.

The home sales price is one of the vital catalysts for a country's economy as urban land value is determinative in both urban planning and real estate activities. An attractive environment is likely to persuade house prices. If so, estimates of the monetary value of such benefit can be derived by careful analysis of home prices. Most of the emergent cities have not yet comprehended that the values of 
green open spaces can contribute in revitalizing communities. Rarely their existence is ignored to consider in the debate of built forms. Communities not often intentionally omit such amenities; rather, people fail to consider them in their planning because they lack direct economic justification for incorporating them into market driven land use decisionmaking or because they are unaware of their values. This is particularly evident in the developing cities like Dhaka where urbanization sprawls extensively. Dhaka Statistical Metropolitan Area (SMA) accommodates 10.7 million people, which is $37.45 \%$ of total urban population of Bangladesh [2]. In this mega city, the numbers of dwelling places are very scarce due to the increasing urban population and congestion. As a result residential areas of Dhaka city are turning into overcrowded, dirty, and unhealthy environment and lack of open spaces. Experts suggested that an ideal city needs to keep its $40 \%-50 \%$ of land green or free. However Dhaka structure plan urges to have $20 \%$ of green spaces for its future generation [3]. In Dhaka urban greenery, park greenery or tree-covered spaces constitutes less than $15 \%$ of the city landscape [4]. According to the DMDP'95, old Dhaka (organically developed neighborhood) has only 5\% and new Dhaka (planned neighborhood) has about $12 \%$ green open space [3]. Shortage of green space due to the population growth and urbanization is considered as the most alarming threat to the living environment of this capital city. Dhaka has experienced, and will continue to experience, a very increased demand for housing. As a result, land is being consumed for housing sectors at rapid rates, often with little attention paid to the protection of the environmental amenities. Dhaka city are failed repeatedly to consider the values of green spaces in their development decisions. As a result, urban expansion takes place in ways that greatly reduce these open spaces with negative environmental, economic, and social consequences. This study is intended to identify and estimate the economic valuation of open spaces specially parks and water bodies of two different urban residential neighborhoods of Dhaka city in Economic terms.

Studies shows that hedonic price method is the most commonly employed method which aims to value open green spaces by measuring their impacts on property values. Estimates of the economic values or amenity benefits of urban parks and public open spaces have emerged recently [1, 5-10]. Previous research revealed that the price of a house increases with its proximity to nearby parks $[5,7,9,11,12]$. Similarly, other studies indicated that increasing the size of urban parks increases the housing values nearby [5]. On the contrary $[8,13]$ accounted that the size of urban parks or green areas have no significant amenity value. [1, 14] measured the impacts of different categories of open spaces such as; green belt, neighborhood park and golf course on property values and property tax base applying hedonic price model. Research [15] developed a hedonic model to test the economic value of green areas in Istanbul. The results showed that green areas in different size and types have varying impacts on nearby house values. Applications of the method have focused on the analysis of the value of urban amenities and various land uses such as schools, open spaces [9, 10] urban forests [5, 7], urban wetlands [11], public housing projects, [16], shopping centers, office buildings [17], and the neighborhood effects [18] on house prices. Another study [10] applied hedonic price method to estimate the effect of proximity to different types of open spaces on home sales price. In a hedonic study, [11] analyzed the amenity value of and demands for urban recreation park acre by using a two- stage hedonic model. Most of the hedonic studies discussed above had been analyzed the effect of open space on land value of European real estate market. From the light of the previous hedonic studies, this research has developed an approach which would advance the knowledge about the impact of open space on the residential property values, which will provide the first evidence in Dhaka.

This study was intended to identify and estimate the economic value - according to current scenario - of parks and water bodies of Dhaka at different neighborhoods. The aim of the method is to reveal how much of the deviation in property prices depend on the differences of environmental quality. That is, to estimate the implicit price in monetary terms that individuals are willing to pay to consume the benefits of open spaces [19]. The purpose of this study is to investigate the possible impact of public open spaces on the monetary value of residential properties. Through the use of data from actual market transactions, the effect that housing has on the sale price of properties is determined. Controlling other factors, such as a home's structural, location or neighborhood and amenities or environmental attributes, an econometric model is used to estimate the economic value of each housing attribute, at different neighborhoods of Dhaka city.

In the first stage, fundamental concepts and approaches are evaluated by reviewing related literatures of urban design and environmental economics disciplines. In the second stage, the study analyzes the impact of open space attributes on the price of residential properties. Findings suggested that existence of view from houses also has a positive and significant impact on house prices. Dwellers of both regions of Dhaka city are willing to pay a premium to live in close proximity to the open spaces. But the hedonic price of an urban park size does not have any significant impact on house price. This estimated welfare impact also might be helpful in justifying investment on open space preservation and park management program. Moreover identifying the value of open spaces may provide guidance to the town planners in developing sustainable planning for achieving the maximum benefits from the nearest open spaces.

\section{Objective of the Research}

The purpose of this study is to analyze possible impact of public open spaces on the price of residential properties. Through the use of data from actual market transactions, the effect that housing and lot attributes have on the sale price of properties is investigated. Controlling other factors, such as a home's structural, location or neighborhood and amenities or 
environmental attributes, an econometric model is used to estimate the economic value of each housing attribute. This study was intended to identify and estimate the economic value - according to current scenario - of parks and water bodies of Dhaka at different neighborhoods.

\section{Research Materials and Methodology}

The study is conducted with data from Dhaka cities two different densely grown up neighborhoods, named Dhanmondi and Gulshan. Both are the prime planned residential areas mostly chosen by high class residents for improved facilities and its amenity attractions including urban parks and water bodies of varying size, distributed throughout the neighborhoods and hence provide ideal places for the study of urban open space benefits (Figure 1 and Figure 2). A questionnaire analysis is carried out by estimating the effect on 78 observations in the case of multiownership urban residential properties within these two planned residential neighborhoods.

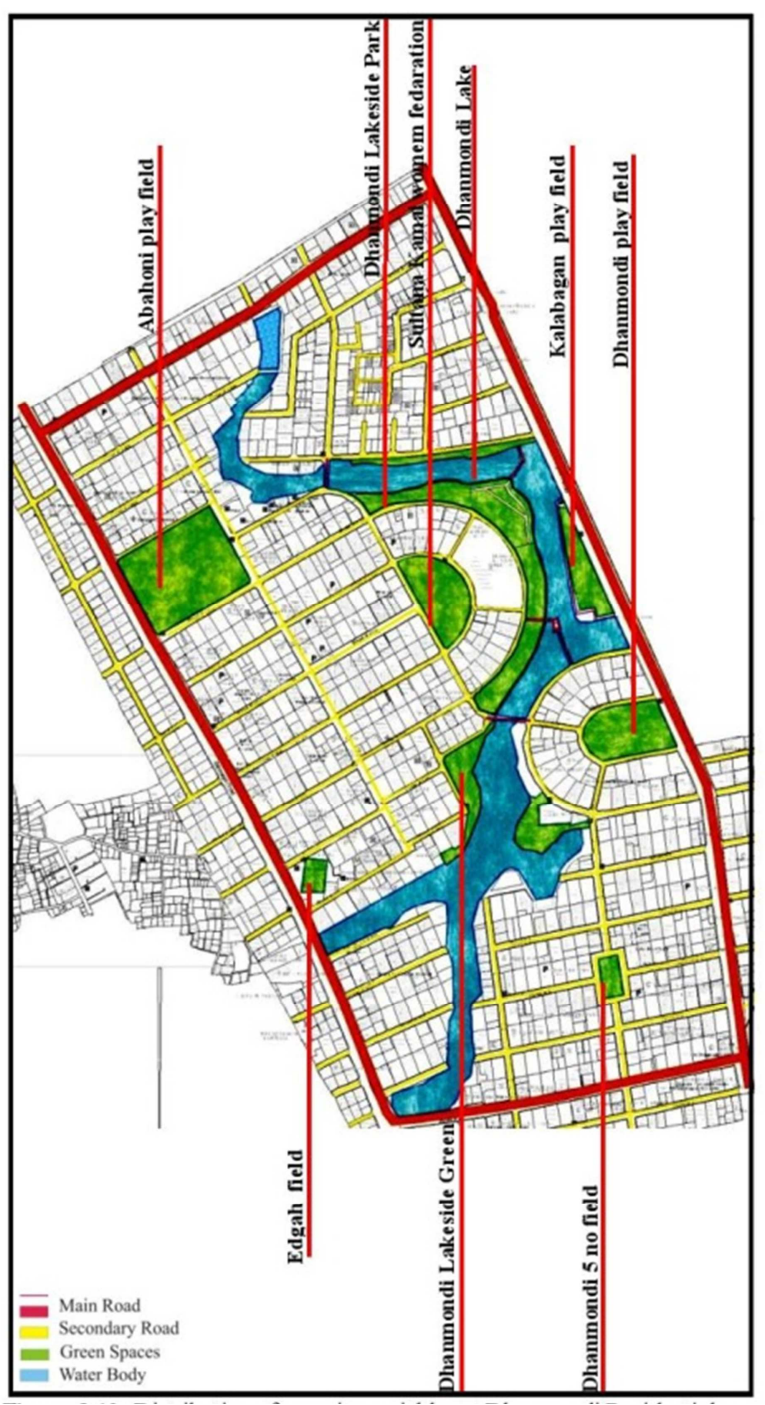

Figure 1. Distribution of Open Spaces in Dhanmondi R/A.
This study has used home transaction data in between the year of 2005 to 2015 , to control for real estate market fluctuations in the city and to make them compatible with the neighborhood data. This time period has been chosen because there was a linear growth of apartments from 1997 to 2007. In 2008 the growth of apartments was higher than any period of the past [20]. The study analyzes the effect of proximity to open space (parks, and water bodies) on home sales price. Households and private developers are the main sources of information. Questionnaire survey is used to collect the data set featuring the price and environmental attributes. Further, some information about the open spaces and locality factors is drawn from maps provided by the Dhaka City Corporation and GIS and from literature review of some research papers.

The surveyed apartments both in Dhanmondi and Gulshan area have different price ranges depending on some factors like the location of the area, services and facilities provided by the authority, design and size of the apartments, orientation, accessibility to school, workplace or nearest open spaces mainly lakes and parks etc, which are discussed in the next section.

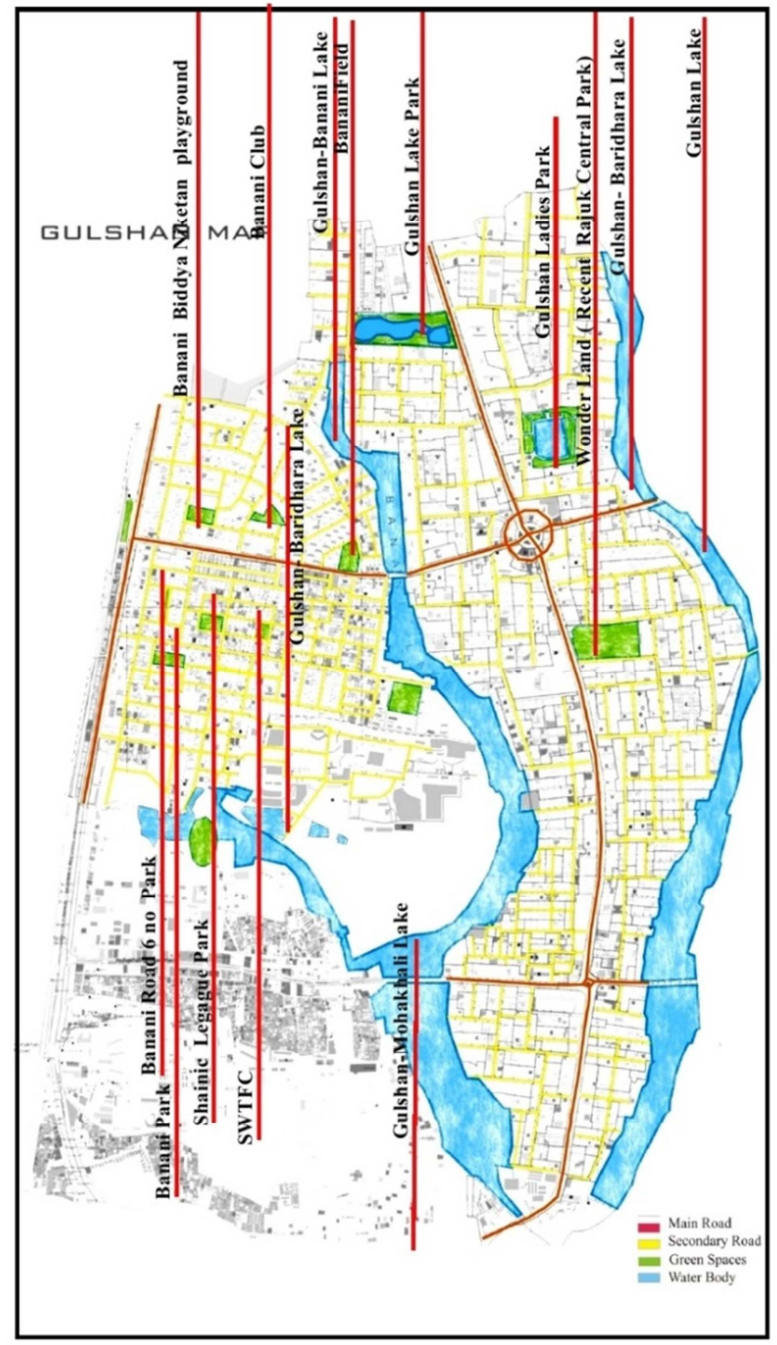

Figure 2. Distribution of Open Spaces in Gulshan Area. 


\section{Research Method}

A Hedonic Price Model is formulated, with the sample of 78 observations (owner occupied multi-storied apartments) and by using least square method, linear regression analysis are operated through E-views statistics package, SPSS. This study uses a typical hedonic equation of housing price in a semi logarithmic form as shown in equation"(1)" below:

$$
\mathrm{Pi}=\beta 0+\sum \beta \mathrm{j} \mathrm{Sij}+\sum \beta \mathrm{kNik}+\sum \beta 1 \mathrm{Ail}+€ \mathrm{i}
$$

Where in equation "(1)", $\mathrm{Pi}$ is the implicit price of the ith house, $\mathrm{Sij}$ represents $\mathrm{jth}$ structural variable, Nik is the measure of the kth neighborhood characteristics, and Ail represents the lth attribute of environmental attributes. Similarly $\beta 0, \beta \mathrm{j}, \quad \beta \mathrm{k}, \beta 1$, represent the corresponding parameters to be estimated, whereas $€ \mathrm{i}$ captures the error term.

Regression is a technique that is used to investigate the effect of one or more predictor or independent variables on an outcome variable. Within the context of regression analysis, an output table is generated which includes information about the quantity of variance that is explained by predictor variables. The first statistic, $\mathrm{R}$, is the multiple correlation coefficients between all of the predictor variables and the dependent variable. The next value, $\mathrm{R}$ Square, is simply the squared value of $\mathrm{R}$. This is frequently used to describe the amount of variation explained by a known set of predictor variables.

\section{Data Analysis}

According to theoretical analysis, variables' set is composed of dependent variable and sets of independent variables. Dependent variable is the Implicit Price of housing unit. Independent variables include three sets of attributes: Structural and Housing variables, Neighborhood variables, Urban Amenity or Environmental variables.

The amenity or environmental variables are the focus variable of the study. All the proximity measures of Urban Amenity variables such as distance of parks and lakes from houses are generated using Arc View GIS 3.2. The size of open spaces is ensured from various sources. Size of Gulshan-Mahakhali, Gulshan-Baridhara and Gulshan-Banani lakes are determined from DMDP structure plan of RAJUK (DAP, 95). Dhanmondi lake size is confirmed from a research paper [21]. The size of other open spaces (parks and play fields) is defined from a thesis paper [22].

Table 1 below presents the frequency analysis results for view of amenity characteristics, where view is the only categorical amenity variable in this study.

Table 1. Frequency Analyses of Categorical Variables for Amenity characteristics.

\begin{tabular}{lllll}
\hline Variables & Category & Frequency & Percentage & Cumulative percentage \\
\hline & No & 40 & 50.6 & 50.6 \\
View (owned house) & Field & 5 & 6.3 & 57.0 \\
& Park & 7 & 8.9 & 65.8 \\
& Lake & 27 & 34.2 & 100.0 \\
\hline
\end{tabular}

Table 2. Descriptive Statistic results for Amenity Variables used in the first-stage Hedonic Model.

\begin{tabular}{lllll}
\hline Variables & N & Minimum & Maximum & Mean \\
\hline Size & 79 & 38794.000 & 6337108.80 & 2707074.600 \\
Distance & 79 & 00 & 1240.40 & 226.7906 \\
Valid N (listwise) & 79 & & & 2396614 \\
\hline
\end{tabular}

Table 2 above presents the descriptive statistics results for amenity variables (size and distance) used to determine the price of housing unit.

As expressed in the hedonic function above; three sets of explanatory variables are used. These include a set of structural variables of the house, a set of neighborhood characteristics and a set of amenity or environmental variables explaining the attributes of the nearest urban parks, lakes and fields. In this study dependent variable is housing unit's implicit price. The Amenity variables are tested only for owner occupied houses. Table 3 bellow, represents R2, Fstatistics and coefficient values for each variable entered the model. The focus variables capturing the Amenity or Environmental characteristics are significant at 5\%-1\% level.

\section{Results from Hedonic Price Method}

In hedonic regression analysis by using 78 observations a price model has been developed where price of housing units is determined as dependent variable and housing units' structural, neighborhood and amenity variables are determined as independent variables. This study focuses on the amenity or environmental characteristics of housing units, since it aims to determine the economic value of open spaces. In this regression model environmental attributes of a housing unit includes view of green open spaces from housing unit (VCA1), size of nearest open spaces from housing unit (VCA2), proximity to the nearest open space from housing unit (VCA3).

Results from Hedonic regression are reported that, houses having the view of nearest park, lake or field - VAN1 have a positive and significant impact on implicit house price at $1 \%$ level. Residents are willing to pay more for houses having open space view. That means houses with open space views especially lake or park views have $14 \%$ higher price than the houses without any open space views (table 4). Size of the open space (park or lake) - VAN2 is positively related to house price. It means increase in size of open spaces nearest to the 
house increase the implicit price; but it does not indicate a statistically significant linear relationship (table 5). In addition, VCA3 means proximity to the nearest urban open space from housing unit, which is negatively significant on house price. Result shows that distance from the house to nearest open space (park, lake or field) are intuitively significant on implicit house price at the $5 \%$ level. The elasticity indicates that one unit (ft) decrease in distance from house to the open space increases the implicit price $0.05 \%$; confirming that proximity to park has the higher value of house price (table 6).

Table 3. Results of Regression Analysis model, significance of parameters at 1\% and 5\% level (marked as dark grey).

\begin{tabular}{|c|c|c|c|c|}
\hline Variables & Coefficients & Standard errors & t-statistic & P-value \\
\hline \multicolumn{5}{|l|}{ Housing unit's Structural Variables } \\
\hline VAS1 (Living area) & 5757.734 & 669.716 & 8.579 & 0.000 \\
\hline VAS2 (Exterior) & 10000000 & 3596750 & 2.811 & 0.006 \\
\hline VAS3 (Bedroom) & 6908865 & 1143144 & 6.044 & 0.000 \\
\hline VAS5 (Land area) & -160601 & 133013.2 & -1.207 & 0.231 \\
\hline VAS6 ( Stories) & 2610903 & 3700288 & 0.706 & 0.483 \\
\hline VAS7 (Age) & -1831205 & 587195.9 & -3.188 & 0.003 \\
\hline VBN1 (Population density) & 87.236 & 25.682 & 3.397 & 0.001 \\
\hline VBN2 (Poverty) & 163427.6 & 235966.5 & 0.693 & 0.491 \\
\hline VBN3 (Median Age) & -0.006 & 0.009 & -0.654 & 0.515 \\
\hline VBN4 (Vacancy rate) & 48167.976 & 82371.248 & 0.585 & 0.560 \\
\hline VBN5 (Household income) & 151.719 & 31.112 & 0.4 .876 & 0.000 \\
\hline VBN6 (School Attendance) & 148242.3 & 78687.398 & 1.884 & 0.064 \\
\hline VBN7 (Literacy) & -631167 & 320198.8 & -1.971 & 0.052 \\
\hline VBN9 (Housing tenancy status) & 98759.707 & 47330.86 & 2.087 & 0.040 \\
\hline VCA1 (Park /Lake/ Field view) & 1545181 & 494481.9 & 3.125 & 0.000 \\
\hline VCA2 (Park or Lake size) & 0.069 & 0.030 & 0.892 & 0.375 \\
\hline VCA3 (Park/Lake/ Field proximity) & -5811.852 & 2483.569 & -2.340 & 0.022 \\
\hline R- squared & 0.744 & & & \\
\hline Adjusted R- squared & 0.678 & & & \\
\hline F- statistics & 11.247 & & & \\
\hline Number of observations & 78 & & & \\
\hline
\end{tabular}

Table 4. Regression analysis results between price and view of nearest open spaces from owner occupied houses.

\begin{tabular}{lllll}
\hline \multirow{2}{*}{ Model } & \multicolumn{2}{l}{ Unstandardized Coefficients } & \multicolumn{2}{c}{ Standardized Coefficients } \\
\cline { 2 - 3 } & B & Std. Error & Beta & \multirow{2}{*}{ Significance } \\
\hline (Constant) & 7427233.811 & 1310639.669 & & 5.667 \\
VIEW & 1545181.167 & 494481.858 & .335 & .000 \\
\hline
\end{tabular}

Table 5. Regression analysis results between price and distance of nearest open spaces from owner occupied houses.

\begin{tabular}{lllll}
\hline \multirow{2}{*}{ Model } & \multicolumn{2}{l}{ Unstandardized Coefficients } & \multicolumn{2}{c}{ Standardized Coefficients } \\
\cline { 2 - 3 } & B & Std. Error & Beta & Significance \\
\hline (Constant) & 10199513.388 & 1087577.640 & & 9.378 \\
SIZE & .269 & .302 & .101 & .000 \\
\hline
\end{tabular}

Table 6. Regression analysis results between price and distance of nearest open spaces from owner occupied houses.

\begin{tabular}{lllll}
\hline \multirow{2}{*}{ Model } & \multicolumn{2}{l}{ Unstandardized Coefficients } & \multicolumn{2}{c}{ Standardized Coefficients } \\
\cline { 2 - 3 } & B & Std. Error & Beta & Significance \\
\hline (Constant) & 12246414.046 & 896526.186 & & 13.660 \\
DISTANCE & -5811.852 & 2483.569 & -.258 & -000 \\
\hline
\end{tabular}

\section{Discussion}

The findings of the research showed that open space has a relative measurable economic value. The empirical evidence concludes that open spaces within the residential neighborhoods have a positive effect on the property price. Homebuyers are willing to pay a premium for the open spaces when they purchase the properties. The results prove that presence of open space has a significant impact on property prices of the two selected residential neighborhoods of Dhaka. This study focuses on the amenity or environmental characteristics of housing units, since it aims to determine the economic value of open spaces. The amenity attributes of house include view and size of nearest open spaces and distance of those open spaces from houses. Existence of open space (especially lake or park) views increases the house price than the houses having no views within the same neighborhoods. Dwellers of both regions are willing to pay a premium to live close to the open spaces. Finally, to understand the factors affecting the impact of open spaces on housing unit's prices, the study revealed that the 
house price differs depending principally on having views of open spaces and its proximity to the housing unit. But the size of an open space does not have any significant impact on house price in this densely built city. As the supply of open spaces is far short of demand in Dhaka city, less choice make it difficult to clearly determine the value of residential properties for size of open spaces.

From all the test results it is found that view of open spaces for owner occupied houses have a positive and significant impact on house price. This indicates that existence of the view of open spaces increase the house price by $14 \%$. In terms of size of nearest open spaces for these houses, the results show a positive impact. But it does not indicate a statistical significant linear relationship. As the supply of open spaces far short of demand, less choice make it difficult to clearly determine the value of residential properties for size of open spaces. The distance of nearest open spaces has a negative but significant impact at owner occupied house prices. This means increasing the distance of nearest open spaces from houses by $1 \mathrm{ft}$, decrease the house price by $0.05 \%$. These test results summarize the findings of the study; which would provide suggestions for policy implications and further researches and sustainable planning.

Most of the previously studied papers showed negative effects on real estate prices that mean people would prefer proximity to parks for recreational opportunities and aesthetic benefits. However, an opposite result for the effect of open space distance on prices is found for the case of Leipzig [23].

The research [24] shows that walk able amenities like parks and restaurants are negatively correlated with house prices in Dortmund. The result explains the house prices not only depend on class of neighbors, presence and accessibility of amenities and public transport and motorway accessibility but the price of the neighboring dwellings also plays an important role.

The research of $[23,25]$ state that surprisingly the size of the nearest UGS (Urban Green Space) has a more relevant impact on the price of the housing than the distance to the nearest UGS. The study result of [25] illustrates that being too close to UGS may also increase residents' exposure to park related disamenities, such as noise and crime. From the research it is also found that the simplest shape (i.e., similar to square) of the nearest UGS, has the highest positive impact on the housing price, as Leipzig has an outstanding abundance of UGS. Similarly Nur Syafiqah A. Samad; et al, explain in their research [26] that the house price in Kuala Lumpur is influenced by the environmental attributes. The study shows that, in Kuala Lumpur reducing the distance of the house location to the nearby open spaces by $10 \mathrm{~m}$ increases the house price by RM 1700. Where as in Dhaka increasing the distance of nearest open spaces from houses by $1 \mathrm{ft}$, the house price decreases by $0.05 \%$ for owned houses.

For UGS size, hedonic studies of $[25,27]$ confirm a positive effect on housing prices. The larger open spaces are more preferable than the smaller one for views, recreational opportunities and greater access to flora and fauna. Residence of the Leipzig are willing to pay higher prices for housing units located next to UGS of small sizes in a case when population density is low and vice versa. This happens because the competition for a public good is rather low (i.e., small UGS) when there is a low population density and there are abundance of UGS in Leipzig. Similarly in the research [26] it is found that increasing the size of the open spaces by $1000 \mathrm{~m}^{2}$ increases the house price by RM 60, 000 .

\section{Conclusion and Recommendation}

Open spaces may contribute to quality of life in urban areas through their various benefits - social, environmental, physical, and economic. Effective urban land use planning and supplying additional acreage of such open spaces will require a clear understanding of their amenity values and demand in the society. Growth of urban population in Dhaka city has increased the demand for land and thus causes a tremendous pressure on open spaces. Spatial planning of the city is repeatedly failed to integrate open spaces due to the limitations in understanding the monitory values. Within the context of the economic valuation of open space, the aim of this study is to understand the impact of public open space on price of residential properties. The real estate is one of the vital catalysts for a country's economy as urban land value is determinative in both urban planning and real estate activities in economies of today's world. To analyze the impact of open space attributes on price of residential properties, an empirical analysis is carried out by employing Hedonic Price Method (HPM) which is estimating the effect of each relevant variable on the price of properties. A linear regression analysis are operated with the sample of 78 observations on two different neighborhoods of Dhaka city while dependent variable to be determined the price of housing units and independent variables include housing units structural, location or neighborhoods and environmental or amenity attributes. In this model the environmental or amenity characteristics (view, size and distance of nearest open spaces) are considered as the focus variables of the study. In Dhaka no research has been carrying out so far on valuation of open spaces in econometric terms by Hedonic Price Method, therefore, overseas studies are tested in Dhaka's urban neighborhood open space context.

Finding of the research put forward that, Urban home owners are willing to pay or value open spaces only for scenic views and living in the closest proximity to the nearest open spaces for more opportunity of better environment for recreational purpose, social interaction, physical and mental benefits. But in case of size of nearest open space does not have any significant impact on house price as there is huge scarcity of open spaces in Dhaka that makes things more valuable. These results might have important implications for real estate design and sustainable land use planning. In the both densely built neighborhood only a few numbers of apartments with high floors and situated at the edges with open areas, such as lakes, urban parks, and playfields. Most of the dwellings are habitually dominated by building views. Proximity to surrounding buildings is accepted although such views might be considered as undesirable. The frequencies of 
small separation between buildings provide less choice for most home-buyers to avoid building scenes out of their windows. In the light of this research results the urban planners and designers might consider the view and proximity measures of open space for a sustainable planning not only from the adjacent plots of open spaces but also from every possible distance or position of the houses. The estimated welfare impact of these houses might also be helpful in justifying investment on open space preservation and park management. Thus the planners and developers should rethink the current allocation of houses near to open spaces in such a way as to ensure added future values. And this impact may also provide guidance in designing citizenfinanced open space preservation or park management programs for Dhaka in particular and other cities nationwide.

\section{References}

[1] Nicholls S. Does Open Space Pay? Measuring the Impacts of Green Spaces on Property Values and the Property Tax Base. $\mathrm{PhD}$ Thesis 2002; Texas A\&M University.

[2] B. B. S. Population Census 2001: National Report (Provisional), Dhaka. Bangladesh Bureau of Statistics 2003.

[3] Mowla Q A. Eco-design Concept in the Design and Management of Dhaka's Urban Open Spaces. 2005.

[4] Nilufar F. Urban life and use of public open space-Study of responsive public open spaces for supporting urban lie in Dhaka city. For urban life, specially Dhaka city: its past, present and future. Asiatic society of Bangladesh 1999; pp 14.

[5] Tyrvainen L. The Amenity Value of the Urban Forest: An Application of the Hedonic Pricing Method. Journal of Landscape and Planning 1997; vol. 37 (3), pp. 211-222.

[6] More T., Stevens. A. and Allen. T P G. Valuation of Urban Parks. Landscape and Urban Planning 1988; vol. 15, pp. 139-152.

[7] Tyrvainen L. and Miettinen A. Property Prices and Urban Forest Amenities. Journal of Environmental Economics and Management 2000; vol. 39 (2), pp. 205-223.

[8] Morancho A B. A Hedonic Valuation of Urban Green Spaces. Landscape and Urban Planning 2003; vol. 66, pp. 35-41.

[9] Anderson S T. and West S E. The Value of Open Space Proximity and Size: City versus Suburbs. Working Paper 2003; Macalester College, St. Paul, MN.

[10] Neelam C P., Donald G H. and Christopher D M. A hedonic analysis of the demand for and benefits of urban recreation parks. Land Use Policy 26 2009; pp 975-983.

[11] Tajima K. New Estimates of the Demand for Urban Green Space: Implications for Valuing the Environmental Benefits of Boston's Big Dig Project. Journal of Urban Affairs 2003; vol. 25 (5), pp. 641-655.

[12] Rabiega W A., Lin T. and Robinson L. M. The Property Value Impacts of Public Housing Projects in Low and Moderate Density Residential Neighborhoods. Land Economics 1984; vol. 60 (2), pp. 174-179.
[13] Thibodeau T G. Estimating the Effect of High-Rise Office Buildings on Residential Property Values. Land Economics 1990; vol. 66 (4), pp. 402-408.

[14] Tse R Y. Estimating Neighborhood Effects in House Prices: Towards a New Hedonic Model Approach. Urban Studies 2002; vol. 29 (7), pp. 1165-1180.

[15] Alkay E. Housing Submarkets in Istanbul. International Real Estate Review 2008; vol. 11 (1) pp. 113-127.

[16] Freeman III A. M., Herriges J A. and Kling C L. The Measurement of Environmental and Resource Values: Theory and Methods (Third Edition). RFF Press. Taylor \& Francis, Oxon and Routledge, NY 2014.

[17] Luttik J. The Value of Trees, Water and Open Space as Reflected by House Prices in the Netherlands. Landscape and Urban Planning 2000; vol. 48 (3) pp. 161-167.

[18] Mahan B L., Polasky S. and Adams R M. Valuing Urban Wetlands: A Property Price Approach. Land Economics 2000; vol. 76 (1), pp. 100-113.

[19] DTLR. Valuing the External Benefits of Undeveloped Land: Main Document. Department for Transport. Local Government and the Regions, U.K 2003.

[20] Toufiq M S. Private Sector Housing. Pearl Publication 2012; ISBN: 978-984-33-5298-9.

[21] Hossain N., Ishtiaque Z. and Apurba. P. Making an Urban Oasis the Use of Space Syntax in Assessing Dhanmondi Lake Revitalization Project in Dhaka, Bangladesh. Proceedings of the 7th International Space Syntax Symposium, Ed Daniel Koch, Lars Marcus and Jesper Steen, Stockholm: KTH, 2009; vol 044 (4).

[22] Afroza A. Factors and Issues Related to Children Play and Their Implications on Play and Recreation Provision in Dhaka City. PhD Thesis, Loughborough University, 2010; pp. 254-261.

[23] Liebelt V.; Bartke S. and Schwarz N. Hedonic Pricing Analysis of the Influence of urban green Spaces onto residential Prices: the Case of Leipzig, Germany. European Planning Studies 2017; vol 25 (11), pp. 133-157.

[24] Wittowsky D.; Hoekveld J.; Welsch J. and Steier M. Residential housing prices: impact of housing characteristics, accessibility and neighboring apartments - a case study of Dortmund, Germany. Urban, Planning and Transport Research 2020, vol. 8 (1, pp. 44-70, ISSN: (Print) 2165-0020 (Online).

[25] Liebelt V.; Bartke S. and Schwarz N. Urban Green Spaces and Housing Prices: An Alternative Perspective. Sustainability, 2019; vol 11 (13), pp 3707.

[26] Samad N. A.; Abdul-Rahim A. S.; Yusof M. J. M. and Tanaka $\mathrm{K}$. Assessing the economic value of urban green spaces in Kuala Lumpur. Environmental Science and Pollution Research 2020; vol 27, pp 10367-10390.

[27] Liebelt V.; Bartke S. and Schwarz N. Revealing preferences for urban green spaces: a scale-sensitive hedonic 7 pricing analysis for the city of Leipzig. Ecological Economics, 2018; vol. 146 pp 536-548. 